\title{
Isolation and Identification of $17 \alpha$ - Ethinylestradiol - Degrading Bacterial Strains from POME and Cow Dung
}

\author{
Yee Ling Lim, Norhashimah Morad, Japareng bin Lalung, Sze Yie Chan, and Siti Aishah Abu Bakar
}

\begin{abstract}
The isolation of $17 \alpha$-Ethinylestradiol (EE2)-degrading bacterial strains was done using samples sourced from Palm Oil Mill Effluent (POME) and fresh cow dung. Screening processes were conducted to identify the potential strains. The three highest potential EE2-degrading bacterial strains obtained from each sample source were selected for further batch experiments. A batch study with the strains fed with only salt medium containing EE2 as the sole carbon source was conducted for 9 days. The bacterial strain isolated from POME that was capable of degrading EE2 of up to $64.0 \%$ at EE2 concentration of $5 \mathrm{mg} / \mathrm{L}$ was identified as Hyphomicrobium facile. The strain isolated from the cow faeces that was capable of degrading EE2 up to $55.1 \%$ at concentration of $10 \mathrm{mg} / \mathrm{L}$ was identified as Enterobacter cloacae.
\end{abstract}

Index Terms-17a- ethinylestradiol, cow dung, Enterobacter cloacae, Hyphomicrobium facile, palm oil mill effluent.

\section{INTRODUCTION}

According to the United States (US) Environmental Protection Agency (EPA), endocrine disruptive chemicals (EDCs) are the exogenous agents that have the ability to influence the production, binding, transport, action, and excretion of natural hormones in the body that are crucial for reproduction, development, homeostasis, and behaviour [1]. EDCs is one of the major focus in the field of current environmental research as they are capable of inducing adverse health effects in an intact organism, or its progeny, resulting in endocrine malfunction [2]. The natural and anthropogenic chemicals exert direct or indirect effects through receptor-mediated processes by resembling endogenous hormones and suppress the regular hormonal activities [3], [4].

Estrogenic EDCs include Estrone $\left(\mathrm{E}_{1}\right)$, estradiol $\left(\mathrm{E}_{2}\right)$, estriol $\left(\mathrm{E}_{3}\right)$, and synthetically prepared, ethinylestradiol $\left(\mathrm{EE}_{2}\right)$, are also known as steroid hormones. They are a family of polycyclic ring structure chemicals that contains a common molecular framework [5]. The presence of EDCs in water bodies is contributed mainly by human and animal excretions as glucuronides and sulphates, which are the inactive polar conjugates [6], [7].

Estrogenic EDCs has harmful effects on the hormonal system and is difficult to remove by common wastewater treatment methods. Thus, many research works have been

Manuscript received April 27, 2015; revised April 7, 2016. This work was supported by Universiti Sains Malaysia in the form of postgraduate fellowship as well as Research University grant 1001/PTEKIND/814138.

The authors are with University Sains Malaysia, Environmental Technology Division, Penang, 11800 Malaysia (e-mail: yeeling_77@yahoo.com,_nhashima@usm.my, japareng@usm.my, cynthia_sze91@hotmail.com, echa2330@yahoo.com). conducted to develop more efficient microbial degradation techniques. However, up to now, only a small number of EE2-degrading microbes were found [8]. Hence, to reduce the potential risk posed by EDCs in treated wastewater which is to be discharged to aquatic environments, their removal is significantly important.

Estrogenic substances released into freshwater environment cause disruptive impacts on native fauna, and this has increased international concern [9]. Synthetic estrogen $17 \alpha$-ethinylestradiol (EE2) can give a negative impact even at nanogram level. It can increase the risk of cancer, decrease egg and sperm production, reduces gamete quality which causes complete feminization of the male fish. EE2 is usually used as the estrogenic component in oral contraceptives. Most women use oral contraceptives to prevent pregnancy and to stabilize the menstrual cycle. This is a large contributor to synthetic EE2 in the environment.

Work on identifying estrogen-degrading microbes has largely concentrated on organisms found in temperate countries. In order for a technique for the removal of EE2 using microbes to be applicable in a certain environment, the microbes chosen should be able to thrive in the climate where the system is implemented. Therefore, local perspective for the biodegration process is important because the functions of bacteria vary in different condition. In this work, we investigate the capability of existing local bacteria to degrade EE2 in a tropical climate. The sources of bacteria are from Palm Oil Mill Effluent (POME) and fresh cow dung. Batch experiments were run to identify the effectiveness of each bacterial strain in reducing the EE2 from aqueous solution.

\section{MethodOLOGY}

\section{A. Preparation of EE2 Stock Solution}

$0.1 \mathrm{~g}$ of synthetic EE2 in powder form (Sigma) was weighed to prepare an EE2 stock solution with concentration of 1000 $\mathrm{mg} / \mathrm{L}$. It was prepared by diluting the powder form of EE2 with methanol (Quality Reagent Chemical, QRëC).

\section{B. Isolation of Bacterial Strain}

Salt medium consisting of Sodium chloride $(\mathrm{NaCl}), 0.1 \mathrm{~g} / \mathrm{L}$, Dipotassium phosphate $\left(\mathrm{K}_{2} \mathrm{HPO}_{4}\right), 1 \mathrm{~g} / \mathrm{L}$, Magnesium Sulphate $\left(\mathrm{MgSO}_{4} \times \mathrm{H}_{2} \mathrm{O}\right), \quad 0.2 \mathrm{~g} / \mathrm{L}, \quad$ Ammonium chloride $\left(\mathrm{NH}_{4}\right) 2 \mathrm{Cl}, 1 \mathrm{~g} / \mathrm{L}$, Ferric chloride $\left(\mathrm{FeCl}_{3}\right), 0.01 \mathrm{~g} / \mathrm{L}$ and Calcium chloride $\left(\mathrm{CaCl}_{2}\right), 0.1 \mathrm{~g} / \mathrm{L}$ are dissolved in $1 \mathrm{~L}$ of ionized water. After the main salt has been prepared, $1 \mathrm{~mL}$ of the trace element is added. The trace element contains Zinc chloride $\left(\mathrm{ZnCl}_{2}\right), 0.01 \mathrm{~g} / \mathrm{L}$, Manganese II sulphate $\left(\mathrm{MnSO}_{4}\right), 0.1 \mathrm{~g} / \mathrm{L}$, Copper II sulphate $\left(\mathrm{CuSO}_{4}\right), 0.392 \mathrm{~g} / \mathrm{L}$, and Nickle II chloride $\left(\mathrm{NiCl}_{2}\right), 0.02 \mathrm{~g} / \mathrm{L}$. The salt medium was then autoclaved for 15 
minutes at temperature of $120^{\circ} \mathrm{C}$. EE2 were then added as the sole carbon source for bacteria growth.

Pour plating and streaking were conducted to obtain single pure colonies. This was followed by the screening process where three bacterial strains (from each source) with three highest percentage removal of EE2 were selected for further batch experiments.

\section{Batch Experiment}

Batch experiments were performed simultaneously using all six bacteria exposed to different concentrations of EE2, i.e. at 2,5 , and $10 \mathrm{mg} / \mathrm{L}$. The experiments were run in triplicates. The bacteria suspension was prepared with 6-7 loops of sample in $20 \mathrm{ml}$ of salt medium. $2 \mathrm{ml}$ of bacteria suspension was transferred to each conical flask. All the conical flasks were randomly distributed and shaken in different orbital shaker at $30^{\circ} \mathrm{C}$ with the rotation speed at $120 \mathrm{rpm}$. The EE2 compound was then analysed by HPLC at 24, 48, 120, and 192 hours.

\section{Fourier Transform Infrared Spectroscopy (FTIR)}

Fourier Transform Infrared (FTIR) spectroscopy (Thermo Scientific) was used to analyze the surface functional groups of EE2. The range used was from $4000 \mathrm{~cm}-1$ to $1000 \mathrm{~cm}-1$.

\section{E. High Performance Liquid Chromatography (HPLC)}

The concentration of EE2 in the wastewater was analyzed using HPLC - Agilent 1260 Infinity. The mobile phase of the HPLC was set to the ratio of $45 \%$ acetonitrile (ACN) and $55 \%$ water $\left(\mathrm{H}_{2} \mathrm{O}\right)$. All mobile phases used were HPLC grade chemicals. The flow rate of the system was set at $1 \mathrm{ml} / \mathrm{min}$ throughout the analysis.

\section{F. Scanning Electron Microscopy (SEM)}

Bacteria sample was prepared in powder form, where the sample is first centrifuged at 1000 RPM for 5 minutes before the retrieved cells were fixed in McDowell-Trumph fixative prepared in $0.1 \mathrm{M}$ phosphate buffer at $4^{\circ} \mathrm{C}$ overnight. This was followed by dehydration of cell pellets using hexamethyldisilazane (HMDS). The coating was then performed by sputter coater (Polaron SC515) before the examination. The shape and the size of bacteria were identified through SEM (FESEF; Leo Supro, Carl-Zeiss SMT) at a working distance of $8 \mathrm{~mm}$.

\section{G. Identification of the EE2 Degrading Microorganism}

Analysis of the partial nucleotide sequence of this bacterium was carried out by the Centre for Chemical Biology (CCB), Penang. Sequencing reactions were performed using Applied Biosystems BigDye terminator chemistry and were run on ABI 3730XL capillary-based DNA sequencer. The process started with the purification of the Polymerase Chain Reaction (PCR) product using the Qiagen PCR Purification Kit. The resulting PCR product was sequenced and aligned through Basic Local Alignment Search Tool (BLAST) Search Engines database using BLAST algorithm. The DNA sequence of the desired strain and the species of the bacteria were obtained.

\section{RESULTS AND DISCUSSION}

\section{A. Fourier Transform Infrared Spectroscopy (FTIR)}

There are three types of Infrared Spectrum which is Near, Mid and Far Infrared. The FTIR mode used was Mid Infrared with the range $4000-650 \mathrm{~cm}^{-1}$ that contains most fundamental normal modes.

From Fig. 1, one of the peaks observed was peak 3330.49 $\mathrm{cm}^{-1}$ which is in the range of $3350-3250 \mathrm{~cm}^{-1}$. It represents an alcohol group where it is the $\mathrm{OH}$ stretch. Another peak detected was $2907.83 \mathrm{~cm}^{-1}$. This peak represents alkyl group because the value is in the range $2980-2580 \mathrm{~cm}^{-1}$. At this peak, the $\mathrm{CH}$ stretch is identified. Whereas, peak at $1642.28 \mathrm{~cm}^{-1}$ represent primary amide groups where the range is 1680-1620 $\mathrm{cm}^{-1}$. Finally, the peak at $1017.75 \mathrm{~cm}^{-1}$ were found to represent the cyclic alcohol with functional group of $-\mathrm{CH}_{3} \mathrm{OH}$.

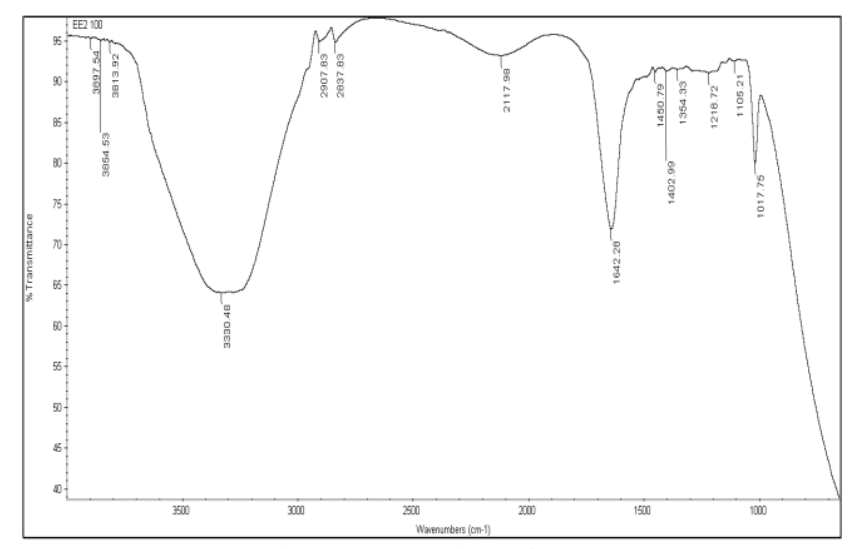

Fig. 1. FTIR analysis of EE2.

\section{B. Description of Colony Morphology}

Six pure and single bacterial colonies were successfully isolated by performing streaking from the POME source and cow faeces. By using raw eye, the colonies formed on the agar surface were examined thoroughly. The bacterial colonies were described in terms of form, surface, texture, color, elevation, and margin. The form refers to the colony shape. Surface indicates the appearance of the bacterial colonies while the texture indicates the consistency of bacterial growth. A description of the colonies is given in Table I.

\section{Degradation of EE2}

Batch experiments were conducted to determine EE2 reduction after 9 days. Samples P-1, P-2, P-3, C-1, C-2, and $\mathrm{C}-3$ were used for further study to investigate the efficiency of EE2 removal. Based on the studies conducted by previous researchers, three different EE2 concentrations were used. The three concentrations used in this study in $\mathrm{mg} / \mathrm{L}$ were 2 [10], 5 [11], and 10 [11], [12]. Optical density of each bacteria in $10 \mathrm{~mL}$ medium was measured at a wavelength of $686 \mathrm{~nm}$ [13] before conducting the batch experiments. This was to ensure that the concentration of bacteria was the same for each concentration. All experiments were conducted in triplicates.

Fig. 2 shows the percentage removal of EE2 of each bacterium at different concentration. At concentration 10 $\mathrm{mg} / \mathrm{L}$, Strain P-1 and C-1 takes the obvious lead with removal at $59.56 \%$ and $55.05 \%$ each. Strain P-1 shows a better removal at all tested concentration compared to other strains. The best EE2 removal by $\mathrm{P}-1$ is at concentration $5 \mathrm{mg} / \mathrm{L}$ where $64.0 \%$ of EE2 removal was achieved. However, the 
effectiveness of C-1 can only be seen in concentration of $10 \mathrm{mg} / \mathrm{L}$.

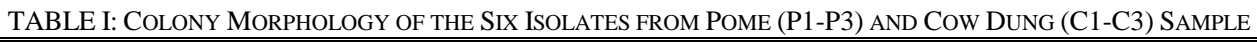

\begin{tabular}{lllllll}
\hline \hline $\begin{array}{l}\text { Sample/ } \\
\text { Morphology }\end{array}$ & Form & Surface & Texture & Colour & Elevation & Margin \\
\hline P-1 & Regular & Rough & Moist & Cloudy & Unbonate & Indulate \\
P-2 & Irregular & Dull & Moist & Cloudy & Unbonate & Indulate \\
P-3 & Regular & Wrinkled & Dry & Cloudy & Flat & Indulate \\
C-1 & Irregular & Rough & Moist & Cloudy (red) & Raised & Lobate \\
C-2 & Irregular & Rough & Moist & Cloudy (white) & Unbonate & Lobate \\
C-3 & Irregular & Rough & Moist & Opaque (dark yellow) & Flat & Undulate (wavy) \\
\hline
\end{tabular}

Strain C-2 and C-3 showed a rather steady equilibrium after 48 hours. This is in agreement with Ren et al. [8] which showed a lag phase of about two days in EE2 degradation. The reason for this lag is that bacteria require time to adapt and grow in the medium when inoculated into fresh medium. When there is sufficient food, the bacteria utilize the food source to enhance growth. The percentage removal increases gradually because EE2, which serves as the sole carbon source, is consumed by bacteria in order to achieve adequate growth as indicated by a decrease in EE2 concentration.

From all the three tested concentration, an overall of better removal is observed at concentration of $10 \mathrm{mg} / \mathrm{L}$. This may due to the easy availability of carbon food source for their growth.

\section{Bacteria Identification}

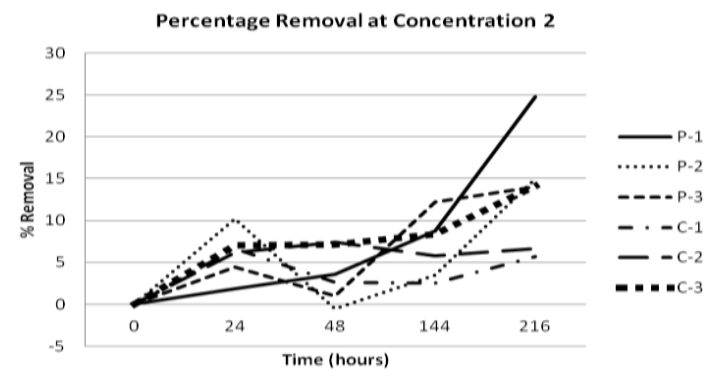

(a)

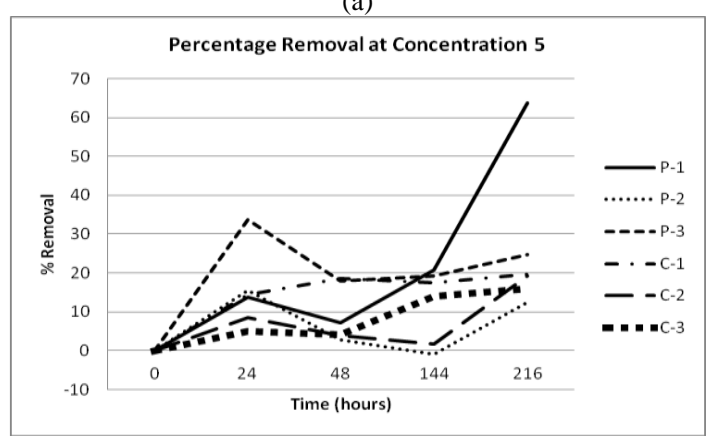

(b)

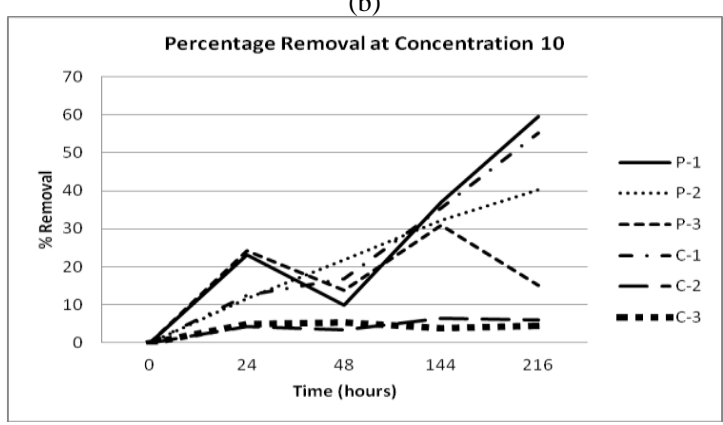

(c)

Fig. 2. Degradation percentage of EE2 at three different concentration.

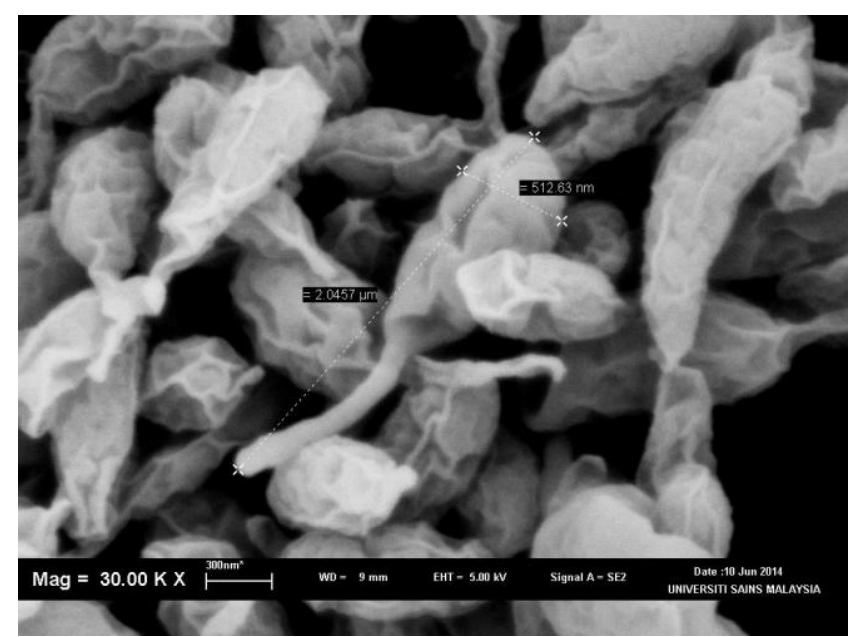

Fig. 3. SEM image of Hyphomicrobium facile at 30K magnification.

TABLE II: PARTIAL NUCLEOTIDE SEQUENCE OF HYPHOMICROBIUM FACILE CGCCCGAGAGGGGAAAGATTTATCGCTATAGGATGGGCCCGCGT AGGATTAGCTTGTTGGTGAGGTAATGGCTCACCAAGGCGACGATC CTTAGCTGGTTTGAGAGAACGACCAGCCACACTGGGTGTGAGAC ACGGCCCAGACTCCTACGGGAGGCAGCAGTGGGGAATATTGGAC AATGGGCGCAAGCCTGATCCAGCCATGCCGCGTGAGTGATGAAG GCCTTAGGGTTGTAAAGCTCTTTTGCCGGGGACGATAATGACGGT ACCCGGAGAAATAAGTCCCGGCTAACTTCGTGCCAGCAGCCGCG GTAATACGAAGGGGACTAGCGTTGTTCGGAATCACTGGGCGTAA AGCGCACGTAGGTGGATTTGTAAGTCAGGGGTGAAATCCCGGGG CTCAACCTCGGGAACTGCCTTTTGATACTGCAAGGTCTTGAGTCC GATAGAGGTGGGGTGGAATTCCTAGGTGTAAGAGGTGAAATTCGT AGATATTAGCCTCCTTGCGGTTAGCGCACCGTTTTAGGGTAAGAC CAACTCCCATGGTGTGACGGGCGGTGTGTACAAGGCCCGGGAAC GTATTCACCGCGCCATGCTGATGCGCGATTACTAGCGATTCCGAC TTCATGAGGTCGAGTTGCAGACCTCAATCTGAACTGAGACGGCTT TTTGCGATTAGCGCCCTATTGCTAGGTGGCTGCGCATTGTCACCG CCATTGTAGCACGTGTGTAGCCCAGCCCGTAAGGGCCATGATGAC TTGACGTCATCCCCACCTTCCTCCGGCTTATCACCGGCAGTCCCA CTAGAGTGCCCAACTTAATGATGGCAACTAATGGCGAGGGTTGCG CTCGTTGCGGGACTTAACCCAACATCTCACGACACGAGCTGACGA CAGCCATGCAGCACCTGTCCCACTGTCCATTGCTGGAATTCCCGG ATCTCTCCAGGCGATCAGTGAATGTCAAGAGCTGGTAAGGTTCTT CGCGTTGCGTCGAATTAAACCACATGCTCCACCGCTTGTGCGGGC CCCCGTCAATTCCTTTGAGTTTTAACCTTGCGGCCGTACTCCCCAG GCGGGATGCTTAATGCGTTAGCTGCGCCACCGAATAGCAAGCTAT CCGACGGCTAGCATCCATCGTTTACGGCGTGGACTACCAAGGTAT CTAATCCCTGTTTGCTCCCCACGCTTTCGCACCTT

The Strain P-1 from POME was identified as Hyphomicrobium facile and the strain C-1 from fresh cow faeces was identified as Enterobacter cloacae.

In Fig. 3, the SEM image of Hyphomicrobium facile shows a rod shape bacteria with flagella at the magnification of 30k. The size of Hyphomicrobium facile at the upper rod shaped cross section is $5.1263 \times 10-7 \mathrm{~m}(512.63 \mathrm{~nm})$, and its flagella is at $2.0457 \times 10-6 \mathrm{~m}(2.0457 \mu \mathrm{m})$.

DNA sequencing for Hyphomicrobium facile which gives 
the best EE2 removal of $64.0 \%$ on the other hand is shown in Table II.

\section{CONCLUSIONS}

Three potential EE2 degrading strains from POME and three from cow dung were isolated and studied. Two strains that gave the best highest removal of EE2 at the given conditions were identified as Hyphomicrobium facile, that was able to degrade $64 \%$ of EE2 at $5 \mathrm{mg} / \mathrm{L}$ after 9 days and Enterobacter cloacae, that was able to degrade $55 \%$ of EE2 at $10 \mathrm{mg} / \mathrm{L}$ after 9 days. The range of removal percentage for Hyphomicrobium facile at different concentrations of EE2, was $25-60 \%$, while for Enterobacter cloacae, the range was $6-20 \%$.

\section{ACKNOWLEDGEMENTS}

The authors gratefully acknowledge financial support from Universiti Sains Malaysia in the form of postgraduate fellowship as well as Research University grant 1001/PTEKIND/814138, which has resulted in this paper. The authors also acknowledge support and advice from the research staff and fellow postgraduate students during the course of this work.

\section{REFERENCES}

[1] USEPA, "Special report on environmental endocrine disruption: An effects assessment and analysis," Washington, DC, 1997.

[2] Y. Zhang and J. L. Zhou, "Removal of estrone and 17[beta]-estradiol from water by adsorption," Water Res., vol. 16. pp. 3991-4003, 2005.

[3] T. A. Roepke, M. J. Snyder, and G. N. Cherr, "Estradiol and endocrine disrupting compounds adversely affect development of sea urchin embryos at environmentally relevant concentrations," Aquat. Toxicol, vol. 2, pp. 155-173, 2005.

[4] A. K. Kumar, S. V. Mohan, and P. N. Sarma, "Sorptive removal of endocrine-disruptive compound (estriol, E3) from aqueous phase by batch and column studies: Kinetic and mechanistic evaluation," $J$. Hazard. Mater, vol. 2-3, pp. 820-828, 2009.

[5] R. D. Briciu, A. Kot-Wasik, and J. Namiesnik, "Analytical challenges and recent advances in the determination of estrogens in water environments," J. Chromatogr. Sci., vol. 2, pp. 127-139, 2009.

[6] T. A. Ternes, P. Kreckel, and J. Mueller, "Behaviour and occurrence of estrogens in municipal sewage treatment plants - II. Aerobic batch experiments with activated sludge," The Science of The Total Environment, vol. 1-2, pp. 91-99, 1999.

[7] J. Shi, S. Fujisawa, S. Nakai, and M. Hosomi, "Biodegradation of natural and synthetic estrogens by nitrifying activated sludge and ammonia-oxidizing bacterium Nitrosomonas europaea," Water Res., vol. 9, pp. 2323-2330, 2004.

[8] R. Haiyan, J. Shulan, N. ud din Ahmad, W. Dao, and C. Chengwu, "Degradation characteristics and metabolic pathway of 17 $\alpha$-ethynylestradiol by Sphingobacterium sp. JCR5," Chemosphere, vol. 2, pp. 340-346, 2007.

[9] M. D. Jurgens, K. I. E. Holthaus, A. C. Johnson, J. J. L. Smith, M. Hetheridge, and R. J. Williams, "The potential for estradiol and ethinylestradiol degradation in English rivers," Environ. Toxicol. Chem., vol. 3, pp. 480-488, 2002.

[10] P. Thayanukul, K. S. Zang, T. Janhom, F. Kurisu, I. Kasuga, and H. Furumai, "Concentration-dependent response of estrone-degrading bacterial community in activated sludge analyzed by microautoradiography-fluorescence in situ hybridization," Water Res., vol. 17, pp. 4878-4887, 2010.

[11] H. B. Lee and D. Liu, "Degradation of 17/-Estradiol and its metabolites by sewage bacteria," Water, Air, Soil Pollut., vol. 1-4, pp. 351-366, 2002.

[12] P. Blánquez and B. Guieysse, "Continuous biodegradation of $17 \beta$-estradiol and $17 \alpha$-ethynylestradiol by Trametes versicolor," $J$. Hazard. Mater, vol. 2, pp. 459-462, 2008.

[13] H. J. Benson, Microbiological Applications: Laboratory Manual in General Microbiology, McGraw-Hill, pp. 2002.

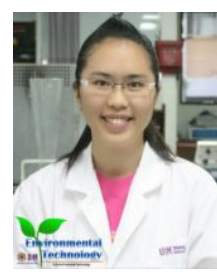

Yee Ling Lim graduated with a B.Tech in Environmental Technology Division from University Sains Malaysia. She is currently a $\mathrm{PhD}$ candidate in the Environmental Divison of School Industrial Technology, University Sains Malaysia as well.

Her research work focuses mostly on the wastewater treatment technology, which include physical/chemical treatment as well as biological treatment.

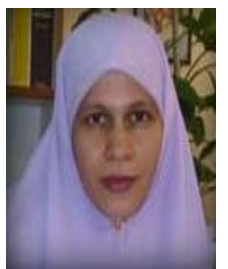

Norhashimah Morad is a professor in the Environmental Technology Division, School of Industrial Technology, University Sains Malaysia. She graduated with her bachelor degree from Unversiy of Missouri, Columbia, USA. She then secures her PhD from University of Sheffield, UK, majoring in control engineering, under the Commonwealth Scholarship.

Her current research work mainly focuses on phytoremediation and new methods and materials in biological and chemical wastewater treatment, life cycle assessment, and intelligent systems.

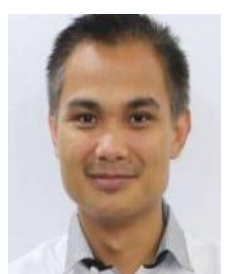

Japareng bin Lalung is a senior lecturer in School of Industrial Technology, University Sains Malaysia. He graduated with his bachelor degree from Unversiy Malaya, Malaysia. He then secures his master degree from University of Oxford, UK before obtaining his $\mathrm{PhD}$ from University of Leeds, England.

His current research work is main focusing on toxin producing cyanobacteria, molecular microbiology and genetics, water science, policy and management, wetlands management and finally ecology and environmental science.

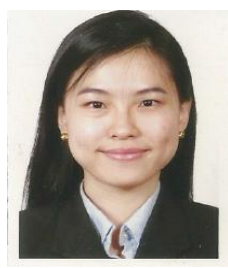

Chan Sze Yie was born in Kuala Lumpur, Malaysia Her bachelor of technology, specialized in environment was received with First Class Honour at Universiti Sains Malaysia, Pulau Pinang, Malaysia in 2014. She is currently pursuing her master in integrated water resources management (IWRM) a Cologne University of Applied Sciences and University of Jordan.

She was an environmental management system (EMS) consultant for consultancy firm for a year. She was also the exhibitor guide for programme 'Seeds of Hope: Vision Of Sustainability, Steps Toward Change'. She also involved in world water day 2014 as a volunteer. Her research interests are wide, including hydrology, hydraulic, flood management and development of a decision support framework for water resources management.

Ms. Sze Yie was selected as the best final year student in the course (2014). She also received scholarship JENESYS 2.0 to Japan in 2014 as a youth exchange.

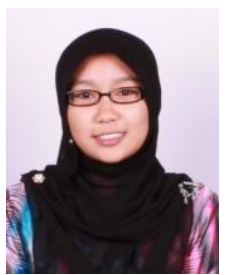

Siti Aishah bt Abu Bakar was born in Bukit Mertajam, Penang on October 15, 1992. She graduated in November 2014 from University of Science, Malaysia and was awarded the B.Sc. degree in environmental technology. Her research work focus mainly on the biological treatment of wastewater. 